\title{
Innovative shore protection for island communities
}

\author{
S. J. Boc \& E. C. Burg \\ US Army Corps of Engineers, Engineer Research and Development \\ Center, Coastal and Hydraulics Laboratory, USA
}

\begin{abstract}
The National Erosion Control Development and Demonstration Program (Section 227) was authorized by the Water Resource and Development Act of 1996 (Public Law 104-303, 110 stat. 3658, dated October 12, 1996) with the goal of fostering development of innovative and non-traditional methods of shoreline erosion control. Sacred Falls State Park on the island of Oahu, Hawaii, was selected as one of the demonstration sites to combat erosion along a section of shoreline that is threatening to encroach upon the state highway. The innovation in shore protection at the Sacred Falls site was chosen to be an offshore reef structure that could be constructed at a remote site with manpower utilizing off the shelf materials and without the use of heavy equipment. Various artificial reef shapes and materials, such as vertical lengths of high-density polyethylene (HDPE) $0.6 \mathrm{~m}$ (24 in) pipe, traffic barriers, and large storage units, were considered and tested in an undistorted linear scale of 1:16 (model:prototype) physical model. Modeling efforts focused on determining barrier arrangements best suited to reduce wave heights leeward of the structure. As a result of this 3-D physical model study, and due to their off the shelf nature, the YODOCK traffic barrier in a three pack was found to be a viable option for the conditions at the site. This low cost and effective erosion reduction technology has applicability in emergency and short term situations in shallow water island environments to protect infrastructure.
\end{abstract}

Keywords: reefs, artificial reefs, shore protection, innovative shore protection, plastic traffic barriers. 


\section{Introduction}

The National Erosion Control Development and Demonstration Program (Section 227) was authorized by the Water Resource and Development Act of 1996 (Public Law 104-303, 110 stat. 3658, dated October 12, 1996). The goal of the program is to foster development of innovative and non-traditional methods of shoreline erosion control through a series of demonstration projects. Sacred Falls State Park, on the island of Oahu, Hawaii, was selected as one of the demonstration sites to combat erosion along a section of shoreline that is threatening to encroach upon the state highway.

Sacred Falls Beach Park, Hauula, (Figure 1) is located at the south end of Makao Beach on the northeast side of the island of Oahu, Hawaii. The project site (Figures 2 and 3) is an approximate 113-m (370-ft) reach of undeveloped shoreline. Seawall-protected private residences bound the small publicly accessible beach at both ends. The beach is very narrow and becomes inundated at high tide. The low-elevation coastal road that services the area is poorly protected with randomly placed boulders and waste concrete piles. Inland of the beach is a narrow coastal plain of alluvium and sand. Kaliuwaá and Kaluanui Stream drains the Sacred Falls area just south of the project site. In the nearshore, a wide fringing coral reef extends along the coast, with 3.7-m (12-ft) water depth located approximately $750 \mathrm{~m}(2,500 \mathrm{ft})$ offshore. The shallow reef

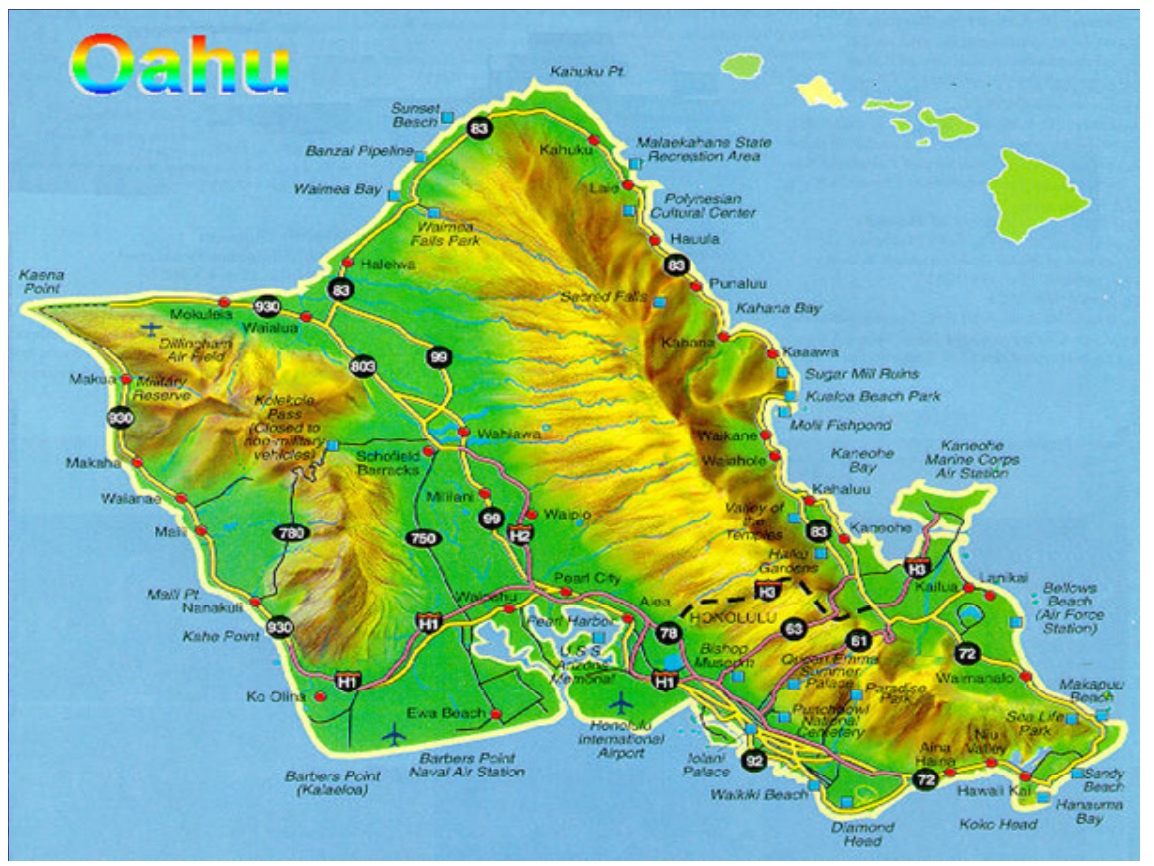

Figure 1: Geographic location. 


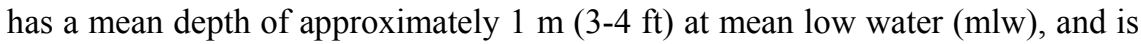
composed of a mixture of coral rubble, sand, and scattered reef blocks over a seabed of hard limestone substrate.

Coral cover is minimal on the shallow reef seaward of the site. The sand, rubble, and boulder bottom has approximately 50 percent algal cover. While fish are sparse in the area, sea urchins and brittle star are common. Both coral and fish density increases on the deep and steep side of Kaluanui Channel, which bisects the reef south of the project.

The Sacred Falls project site is directly exposed to the prevailing trade winds that predominate from April to September. The large winter north swell refracts and diffracts around the island and impacts the project site. Coupled with high winter tides, the shoreline and adjacent coastal highway are occasionally inundated. Tropical storms and hurricanes periodically impact the Hawaiian shores. While these storms produce large surf, the extensive fringing reef at the project site produces a depth limited breaking wave condition that expends most of the wave energy before impacting the shoreline. However numerous shore

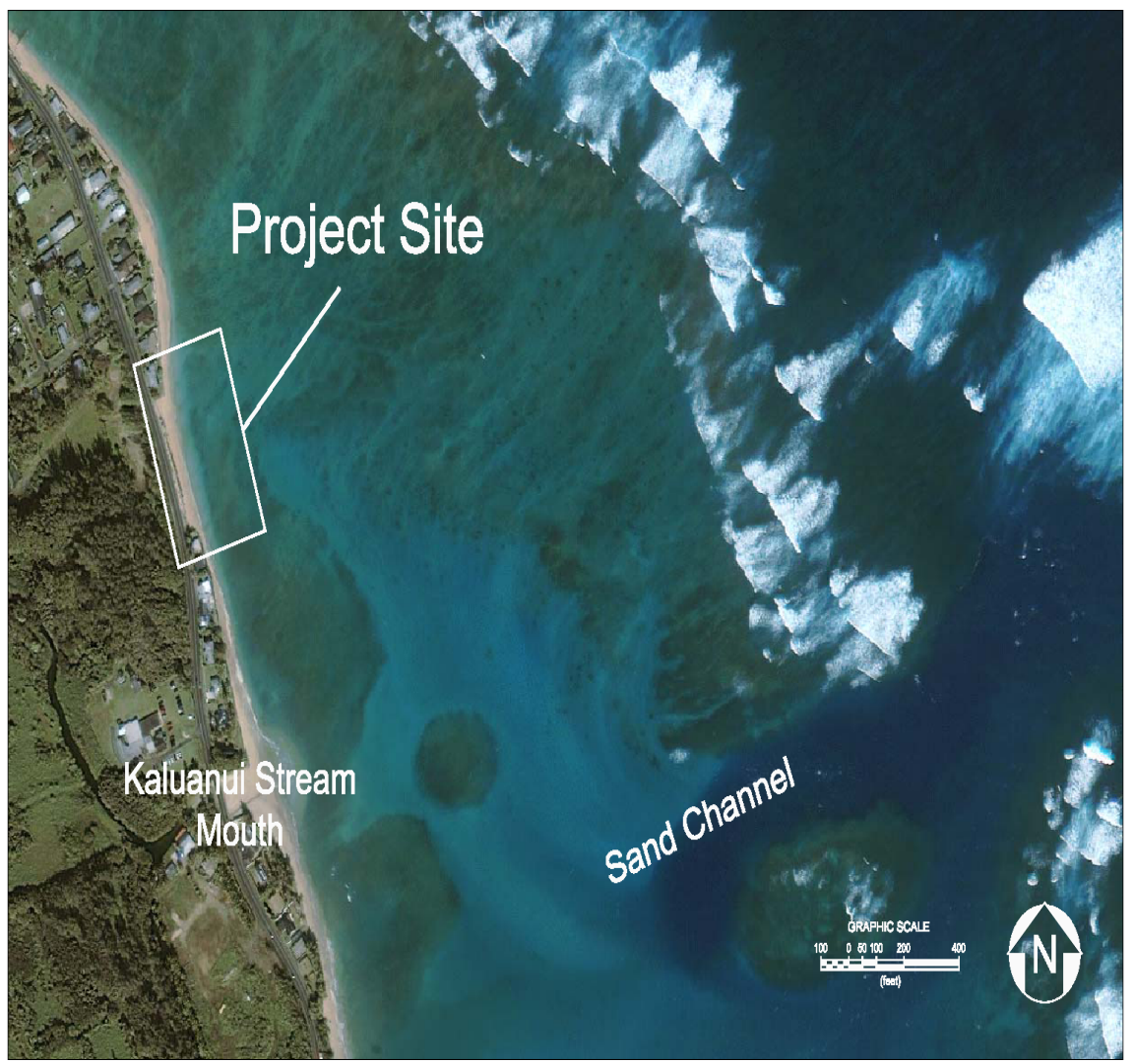

Figure 2: $\quad$ Ikonos satellite photograph of sacred falls site. 
protection structures, of which many show signs of deterioration, both north and south of the project site attest to pervasive yet manageable rates of erosion. The tides are semidiurnal with a mean tide range of $0.6 \mathrm{~m}(2 \mathrm{ft})$.

Continual, yet manageable, erosion of the beach at Sacred Falls Beach Park has reduced beach width to a point that it is almost totally submerged during high tide. Some deterioration of the coast highway is evident. Recreation use of this tourist destination is minimal due to lack of beach width. Shoreline recession must be abated.

The innovation in shore protection at the Sacred Falls site was chosen to be an offshore reef structure that could be constructed at a remote site with manpower utilizing off the shelf materials and without the use of heavy equipment. Various artificial reef shapes and materials such as, vertical lengths of high-density polyethylene (HDPE) $0.6 \mathrm{~m}$ (24 in) pipe, traffic barriers, and large storage units were considered and tested in an undistorted linear scale of 1:16 (model:prototype) physical model. As a result of this 3-D physical model by

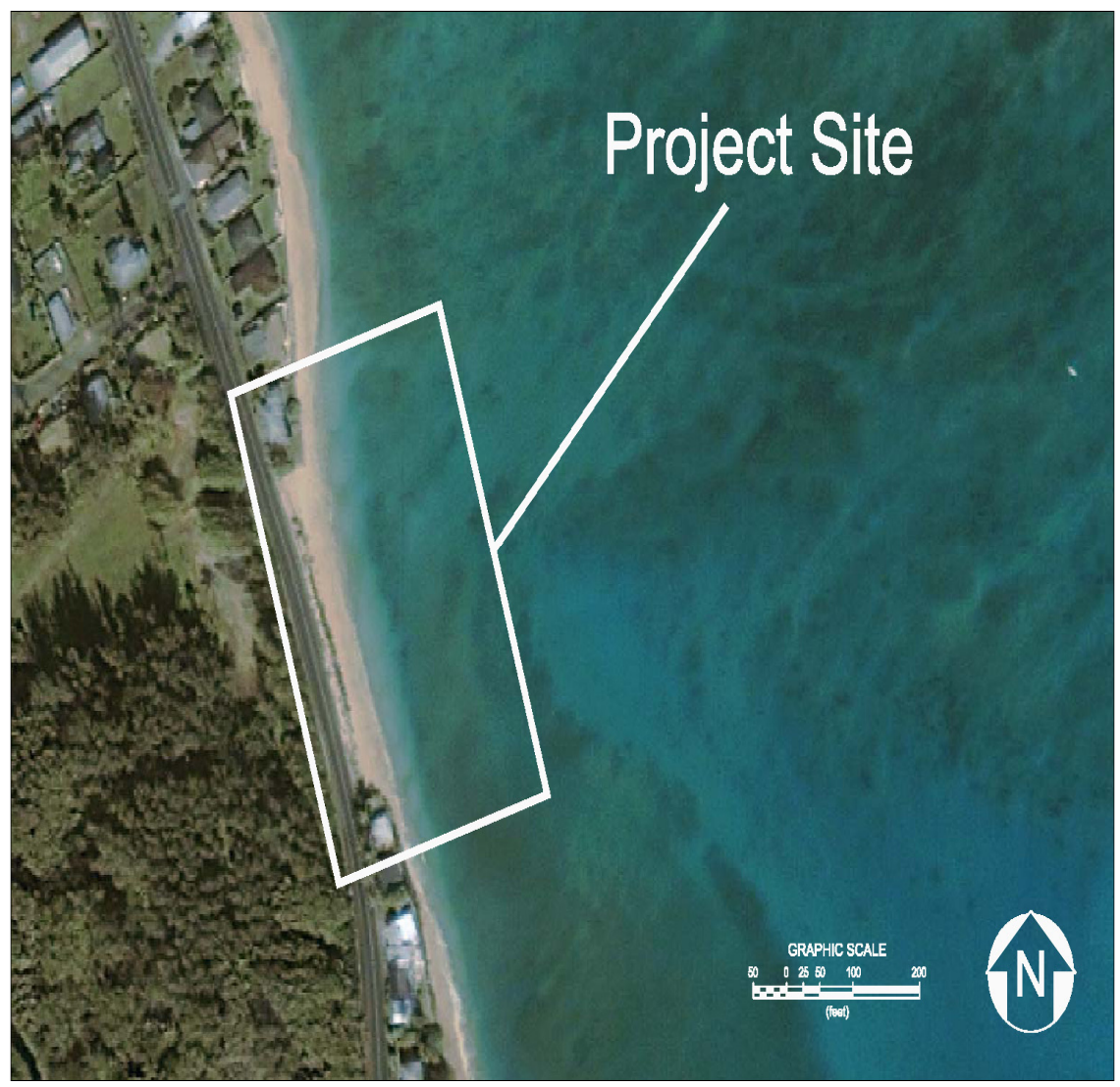

Figure 3: $\quad$ Blow-up of Ikonos image of Sacred Falls site. 
Ward [1] and due to the off the shelf nature, the YODOCK traffic barrier (Figure 4) in a three pack was found to be stable. Further testing in a 1:16 scale flume tank at various water levels, wave heights and period were completed to determine the wave energy reduction effects. Tests were also run in a $0.9 \mathrm{~m}(3$ $\mathrm{ft}$ ) flume to determine wave dissipation over one to four rows of the YODOCK three packs in $+1.2 \mathrm{~m}(+4.0 \mathrm{ft})$ and $+1.8 \mathrm{~m}(+6.0 \mathrm{ft})$ water depths with various deep water wave inputs.

Because the YODOCK traffic barrier is a popular traffic control technology many highway departments already have these in their inventories, it can be made available for emergency shore protection needs very quickly. This low cost and effective erosion reduction technology has applicability in emergency and short term situations in shallow water island environments to protect infrastructure.

\section{Physical model testing}

Physical model testing was conducted at the US Army Engineer Research and Development Center's Coastal and Hydraulics Laboratory in Vicksburg, MS.

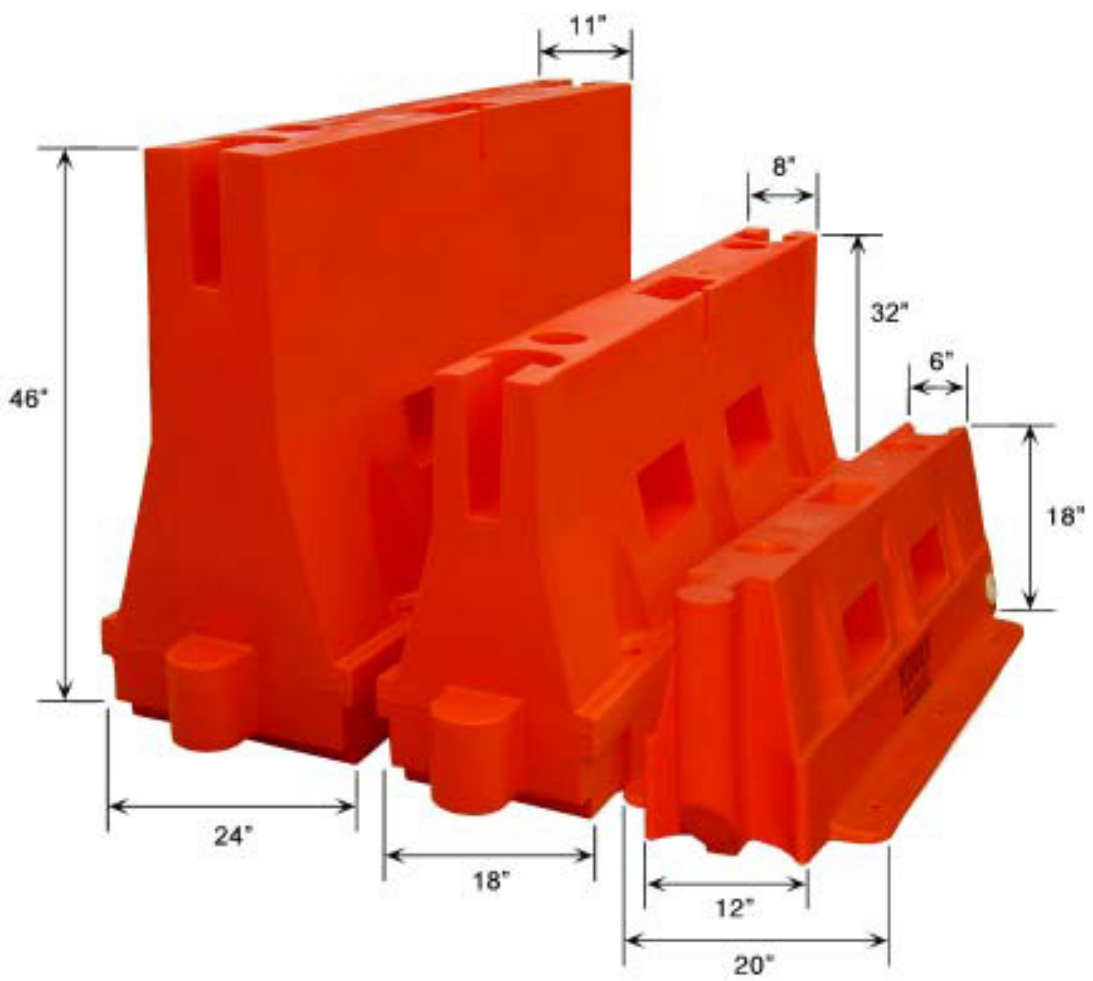

Figure 4: $\quad$ YODOCK traffic barrier. 
All tests were conducted in a glass-walled flume, $45.7 \mathrm{~m}$ by $0.9 \mathrm{~m}$ by $0.6 \mathrm{~m}$ (150 ft by $3 \mathrm{ft}$ by $2 \mathrm{ft})$, ( $\mathrm{LxWxH})$, equipped with a computer controlled, electrohydraulic piston type wave generator. Model testing was conducted at an undistorted linear scale of 1:16 (model:prototype) based on Froude similitude. Model data was collected in English units, but was converted to SI units for the purpose of this paper.

\subsection{Bathymetry}

Bathymetry was installed in the flume to simulate a reef structure with a 1:10 slope preceding $7.6 \mathrm{~m}(25 \mathrm{ft})$ of flat reef in front of the structure, which allowed for natural wave transformation. See Figure 5 for the flume layout.

\subsection{Waves and water levels}

Two water levels were tested, $+1.2 \mathrm{~m}$ and $+1.8 \mathrm{~m}$ to simulate low and high tide conditions, respectively. Three deep water wave height and peak period combinations were tested at both water levels to cover a wide range of possible conditions, see Table 1.

Capacitance-type wave gages were placed seaward and leeward of the structure, with still water elevations being sampled near the toe of the structure. The seaward gage was placed approximately $0.6 \mathrm{~m}(2 \mathrm{ft})$ in front of the structure and the leeward gage was placed $0.2 \mathrm{~m}(0.75 \mathrm{ft})$ behind the structure.

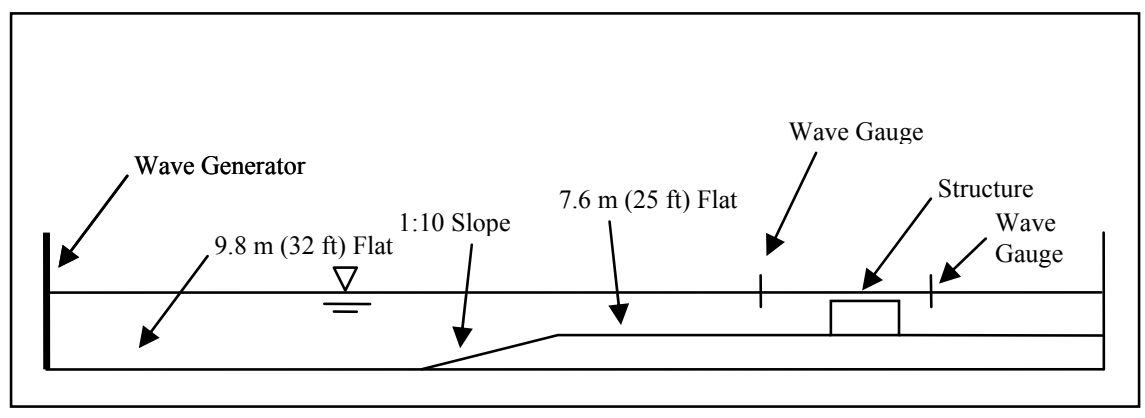

Figure 5: $\quad$ Bathymetry and flume set up (NTS).

Table 1: $\quad$ Wave conditions.

\begin{tabular}{|c|c|}
\hline $\begin{array}{c}\text { Deep Water Wave } \\
\text { Height } H_{m 0}, \mathrm{~m}\end{array}$ & $\begin{array}{c}\text { Peak Wave Period } \\
T_{p}, \mathrm{sec}\end{array}$ \\
\hline 1.1 & 3.6 \\
\hline 1.8 & 14.0 \\
\hline 3.0 & 9.0 \\
\hline
\end{tabular}




\subsection{Testing sequence}

The barriers were grouped in sets of three and tested in both parallel and perpendicular configurations (Figure 6), 1-4 rows deep. An alternate 1-2-1 configuration (front and back rows in parallel set up, two middle rows in perpendicular set up) was also tested for 4 rows. A side channel was constructed in the flume to allow the free flow of water and to prevent water from piling up leeward of the structure, keeping a constant water level seaward of the structure.

\section{Results}

Wave heights were measured seaward and leeward of the structure to determine the reduction in wave height as the wave passed over the barriers. Comparisons were made between the different barrier configurations for corresponding numbers of rows. It was found that the parallel configurations resulted in a greater reduction in wave height than the perpendicular configurations for all wave conditions at both water levels. The 1-2-1 configuration also showed a greater reduction in wave height than the perpendicular set up, but the resulting wave height leeward of the structure was still slightly higher than that of the parallel configuration in all cases. Results from the testing are shown in Table 2 as well as Figures 7-12.

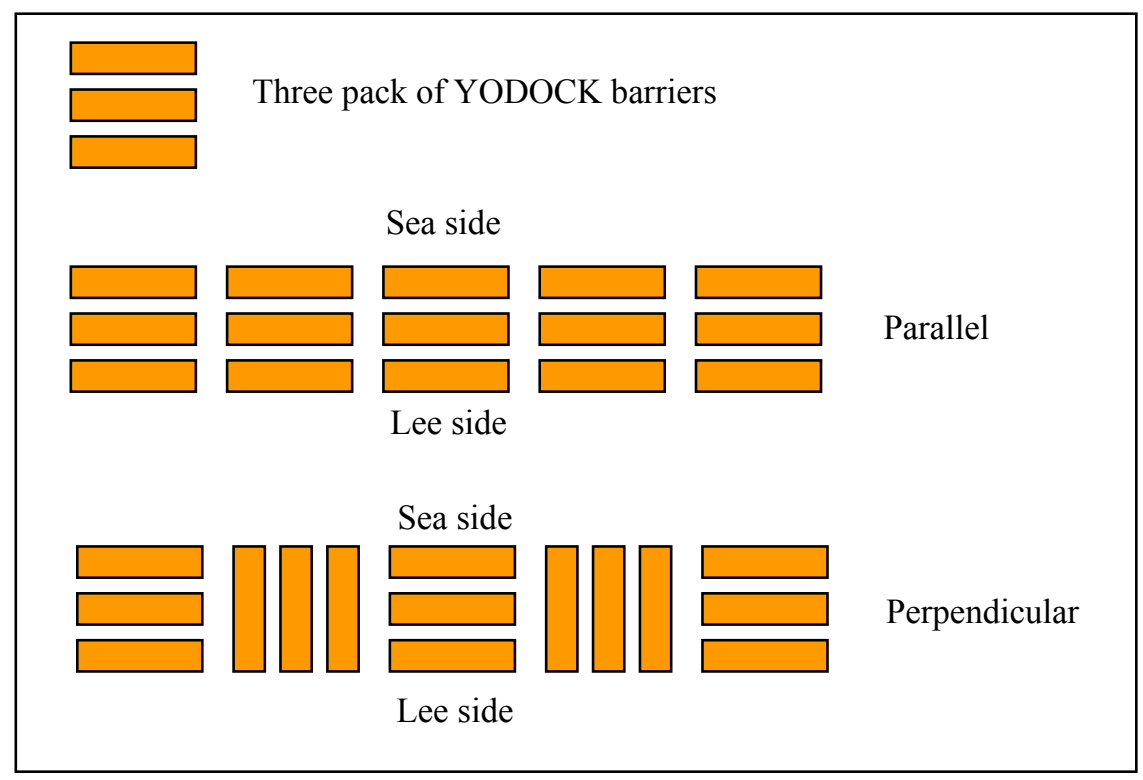

Figure 6: Single row of parallel and perpendicular configurations for three-pack of YODOCK barriers. 
Table 2: $\quad$ Physical model results of leeward wave height for all conditions.

\begin{tabular}{|c|c|c|c|c|c|c|c|c|}
\hline \multirow{2}{*}{$\begin{array}{c}\text { Water } \\
\text { Level, } \mathrm{m}\end{array}$} & \multirow{2}{*}{$\begin{array}{c}\text { Deep } \\
\text { Water } \\
\text { Wave } \\
\text { Height } \\
\mathrm{H}_{\mathrm{m} 0}, \\
\mathrm{~m}\end{array}$} & \multirow{2}{*}{$\begin{array}{c}\text { Peak } \\
\text { Period } \\
\mathrm{T}_{\mathrm{p}}, \\
\text { sec }\end{array}$} & \multirow{2}{*}{$\begin{array}{c}\text { Seaward } \\
\text { Wave } \\
\text { Height, } \\
\text { m }\end{array}$} & \multirow[t]{2}{*}{ Configuration } & \multicolumn{4}{|c|}{ Leeward Wave Height, $\mathrm{m}$} \\
\hline & & & & & $\begin{array}{c}1 \\
\text { Row }\end{array}$ & $\begin{array}{c}2 \\
\text { Rows }\end{array}$ & $\begin{array}{c}3 \\
\text { Rows }\end{array}$ & $\begin{array}{c}4 \\
\text { Rows }\end{array}$ \\
\hline \multirow[t]{9}{*}{+1.2} & \multirow[t]{3}{*}{1.1} & \multirow[t]{3}{*}{3.6} & \multirow[t]{3}{*}{0.5} & Parallel & 0.19 & 0.15 & 0.13 & 0.11 \\
\hline & & & & Perpendicular & 0.27 & 0.22 & 0.18 & 0.16 \\
\hline & & & & $1-2-1$ & - & - & - & 0.12 \\
\hline & \multirow[t]{3}{*}{1.8} & \multirow[t]{3}{*}{14.0} & \multirow[t]{3}{*}{0.6} & Parallel & 0.31 & 0.28 & 0.25 & 0.24 \\
\hline & & & & Perpendicular & 0.39 & 0.33 & 0.30 & 0.27 \\
\hline & & & & $1-2-1$ & - & - & - & 0.25 \\
\hline & \multirow[t]{3}{*}{3.0} & \multirow[t]{3}{*}{9.0} & \multirow[t]{3}{*}{0.6} & Parallel & 0.30 & 0.27 & 0.25 & 0.24 \\
\hline & & & & Perpendicular & 0.37 & 0.32 & 0.29 & 0.27 \\
\hline & & & & $1-2-1$ & - & - & - & 0.25 \\
\hline \multirow[t]{9}{*}{+1.8} & \multirow[t]{3}{*}{1.2} & \multirow[t]{3}{*}{3.6} & \multirow[t]{3}{*}{0.7} & Parallel & 0.55 & 0.53 & 0.50 & 0.48 \\
\hline & & & & Perpendicular & 0.59 & 0.59 & 0.55 & 0.51 \\
\hline & & & & $1-2-1$ & - & - & - & 0.49 \\
\hline & \multirow[t]{3}{*}{1.8} & \multirow[t]{3}{*}{14.0} & \multirow[t]{3}{*}{0.8} & Parallel & 0.62 & 0.60 & 0.57 & 0.54 \\
\hline & & & & Perpendicular & 0.64 & 0.61 & 0.59 & 0.56 \\
\hline & & & & $1-2-1$ & - & - & - & 0.57 \\
\hline & \multirow[t]{3}{*}{3.0} & \multirow[t]{3}{*}{9.0} & \multirow[t]{3}{*}{0.8} & Parallel & 0.60 & 0.59 & 0.56 & 0.54 \\
\hline & & & & Perpendicular & 0.65 & 0.62 & 0.59 & 0.56 \\
\hline & & & & $1-2-1$ & - & - & - & 0.56 \\
\hline
\end{tabular}

\section{Conclusion}

Traditional shore protection utilizes heavy equipment and heavy units to defend against wave attack. The idea of utilizing an "off the shelf" product for shore protection, such as the YODOCK Wall Barrier, and only man power for the installation is a new concept. The YODOCK Wall Barrier was developed for traffic control and protection. Because it is common for these types of barriers to already exist in the inventories of a local communities Department of Transportation or Highway Department, it provides local communities with a low cost and a rapidly emplaced form of shore protection. Our testing has shown that these types of barriers with ballast may be used successfully for shore protection in emergency or short term situations. Long term uses of these units have not been studied but may be possible. Additional studies must be done to test the life expectancy of these plastic barriers in a wave environment. 


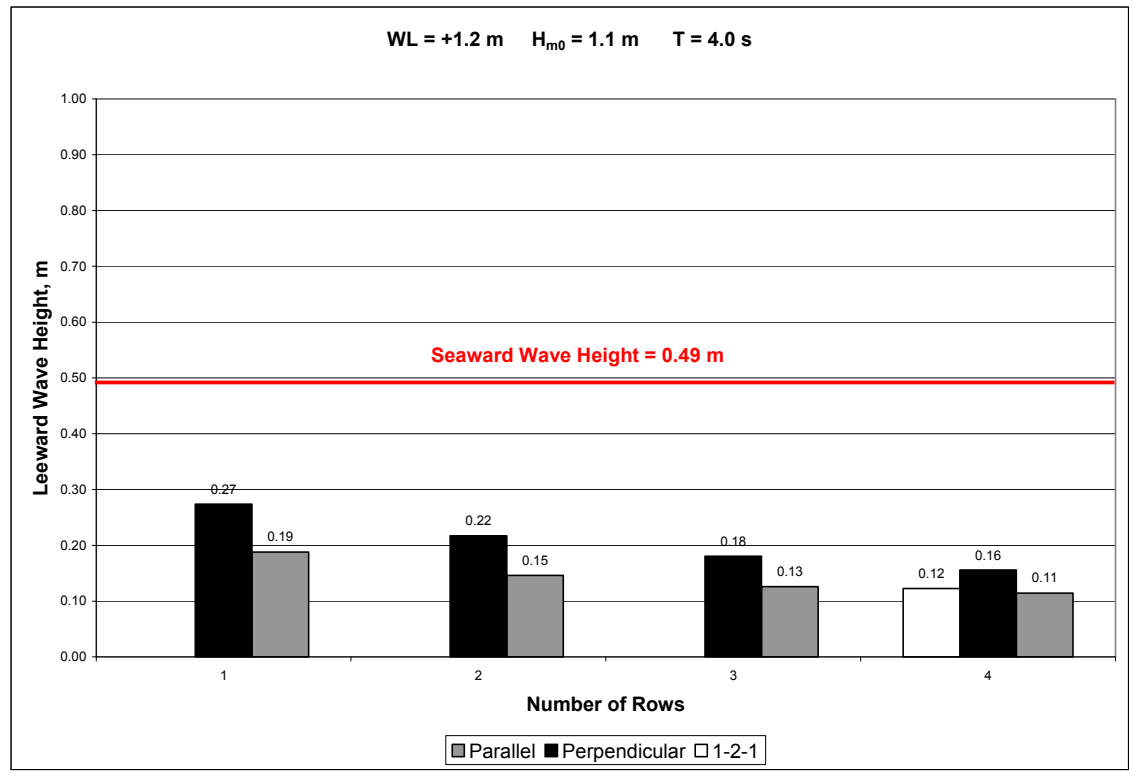

Figure 7: Leeward wave heights for $1.1 \mathrm{~m}, 4.0 \mathrm{sec}$ wave at $+1.2 \mathrm{~m}$.

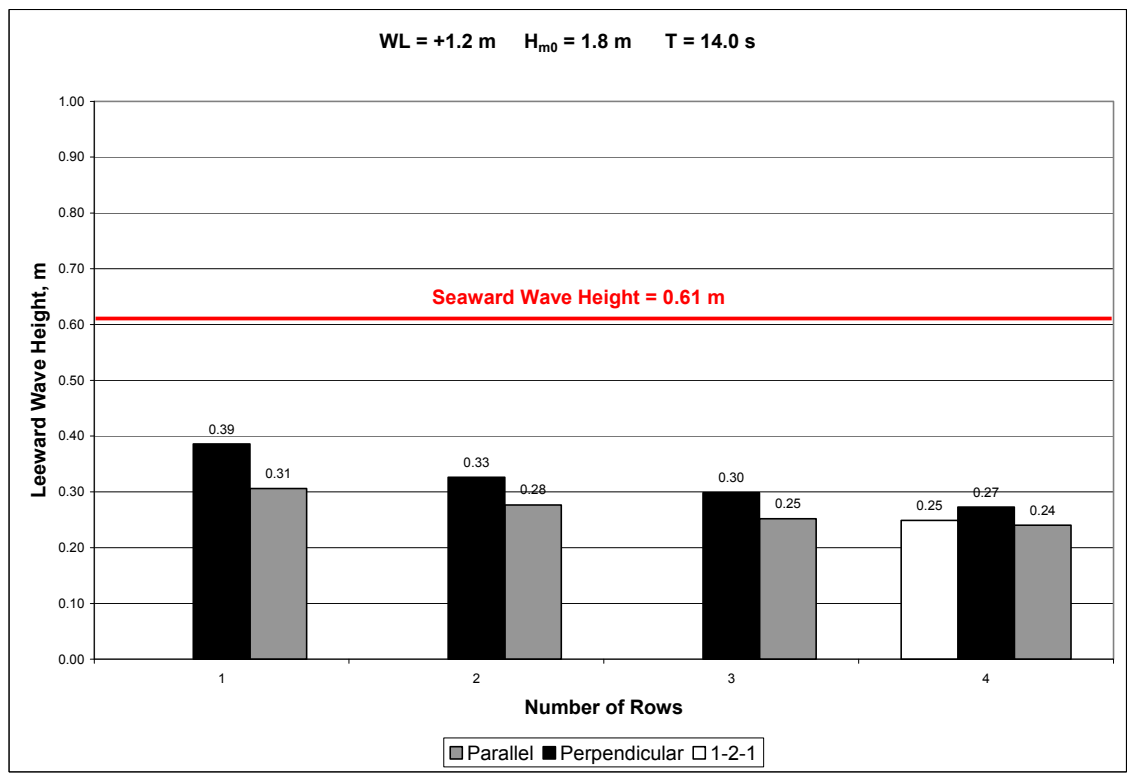

Figure 8: $\quad$ Leeward wave heights for $1.8 \mathrm{~m}, 14.0 \mathrm{sec}$ wave at $+1.2 \mathrm{~m}$. 


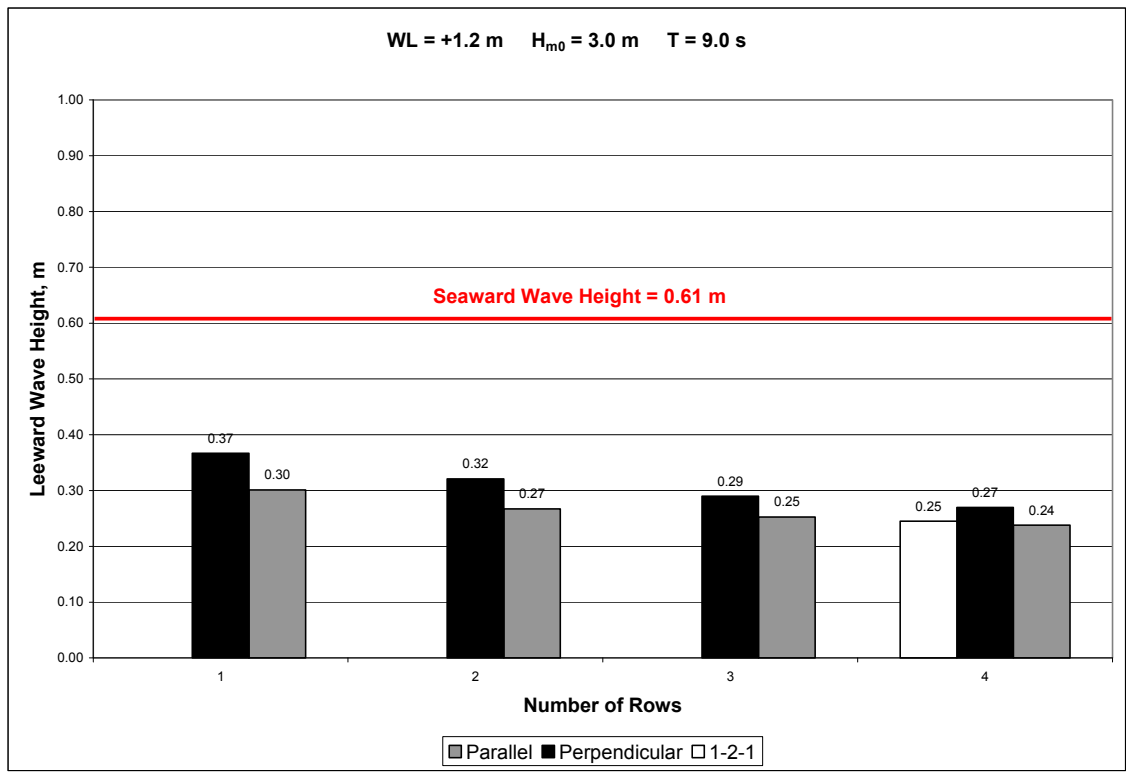

Figure 9: $\quad$ Leeward wave heights for $3.0 \mathrm{~m}, 9.0 \mathrm{sec}$ wave at $+1.2 \mathrm{~m}$.

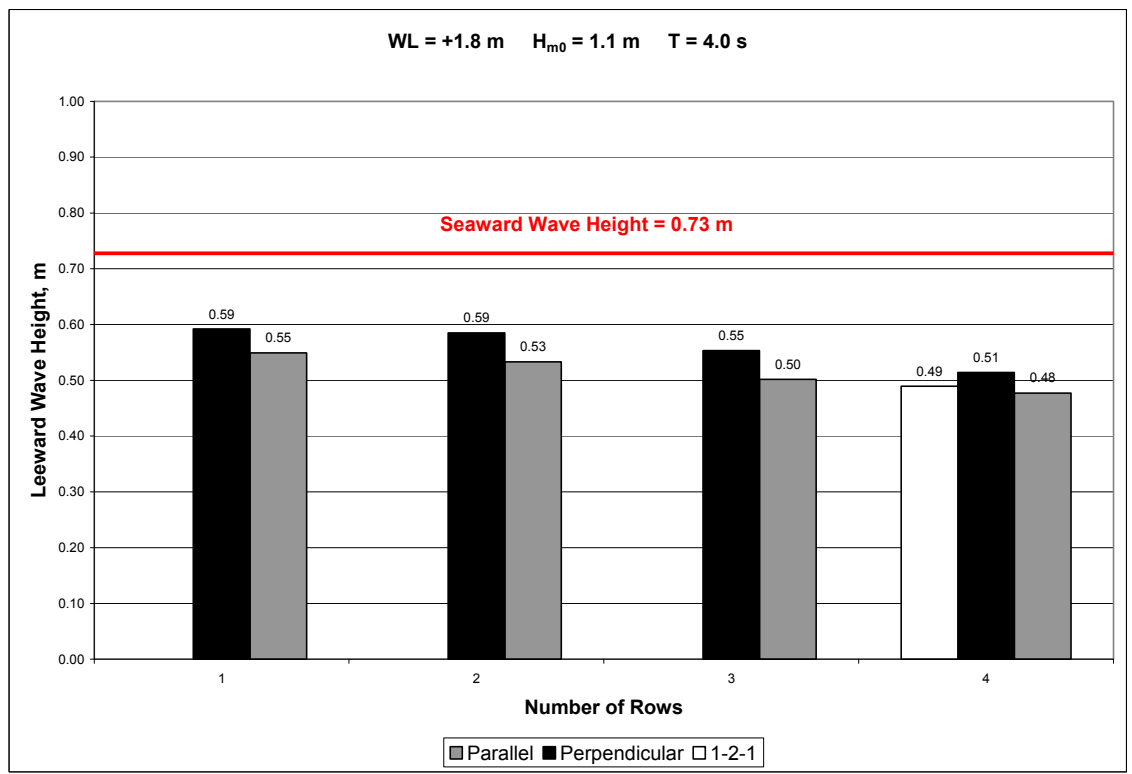

Figure 10: Leeward wave heights for $1.1 \mathrm{~m}, 4.0 \mathrm{sec}$ wave at $+1.8 \mathrm{~m}$. 


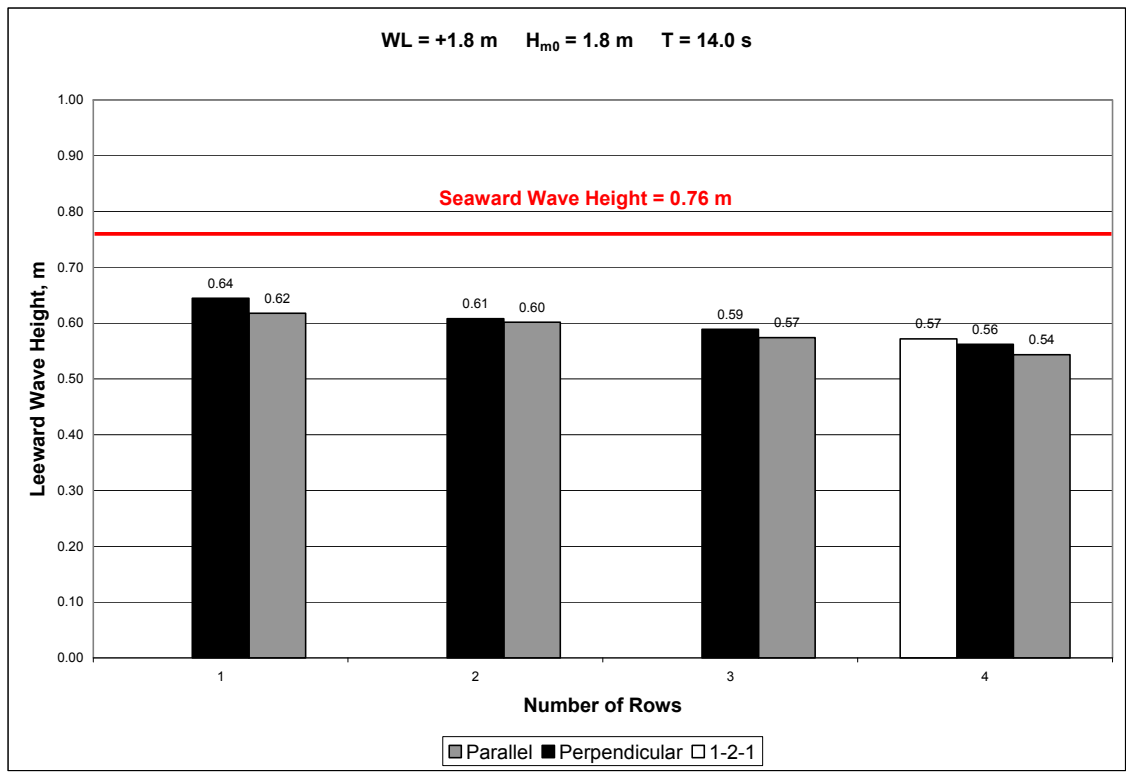

Figure 11: $\quad$ Leeward wave heights for $1.8 \mathrm{~m}, 14.0 \mathrm{sec}$ wave at $+1.8 \mathrm{~m}$.

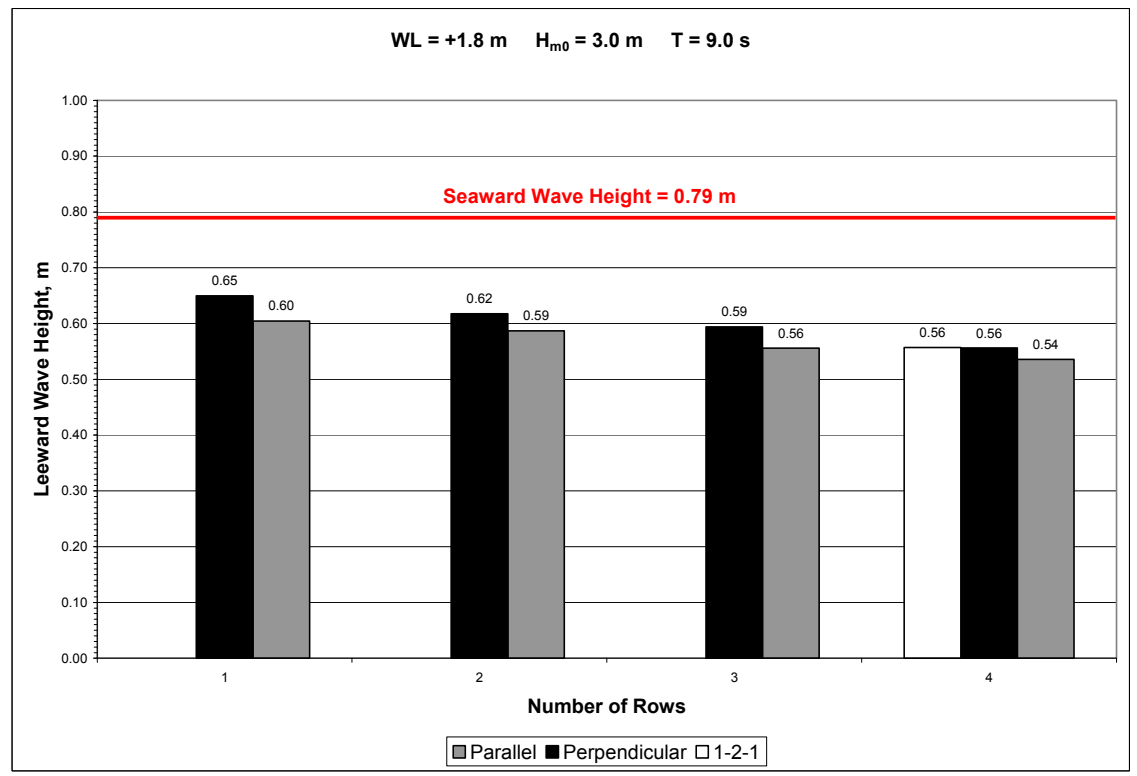

Figure 12: $\quad$ Leeward wave heights for $3.0 \mathrm{~m}, 9.0 \mathrm{sec}$ wave at $+1.8 \mathrm{~m}$. 
Wave testing was completed in a 3-foot flume. As expected wave height reductions were achieved in the lee of the structure. For the 4-foot water depth, the wave heights were reduced by $40 \%$ to $77 \%$. For the 6 -foot water depth, the wave heights were reduced by $16.5 \%$ to $37 \%$. The majority of the variance in the percent of wave height reductions is attributed to the wave period and the water depth over the structure crest. For the longer the wave periods, it was observed that the amount of wave height reduction was reduced. The number of rows of three packs had a minimal impact on the reduction of the wave heights.

A full scale demo of this type of structure is presently being designed and planned for the island of Oahu in the State of Hawaii. The present schedule for the structure installation is early 2010 due to environmental documentation and permits.

\section{Reference}

[1] Ward, D. L., Physical Model Study of an Experimental Breakwater for Sacred Falls, Hawaii, unpublished manuscript, US Army Engineer Research and Development Center, Vicksburg, MS, 2008. 